\title{
The Control System for the X-33 Linear Aerospike Engine
}

\author{
Jerry E. Jackson \\ Rocketdyne, Div, of Boeing \\ 6633 Canoga Ave. \\ Canoga Park, CA 91303 \\ 818-586-7517 \\ jerry.jackson@boeing.com
}

\author{
Erich Espenschied \\ Rocketdyne, Div. of Boeing \\ 6633 Canoga Ave. \\ Canoga Park, CA 91303 \\ 818-586-4848 \\ erich.espenschied@boeing.com
}

\author{
Jeffrey Klop \\ Rocketdyne, Div. of Boeing \\ 6633 Canoga Ave. \\ Canoga Park, CA 91303 \\ 818-586-0662 \\ jeffrey.klop@boeing.com
}

\begin{abstract}
The linear aerospike engine is being developed for single-stage-to-orbit (SSTO) applications. The primary advantages of a linear aerospike engine over a conventionáal bell nozzle engine include altitude compensation, which provides enhanced performance, and lower vehicle weight resulting from the integration of the engine into the vehicle structure. A feature of this integration is the ability to provide thrust vector control (TVC) by differential throttling of the engine combustion elements, rather than the more conventional approach of gimballing the entire engine. An analysis of the $\mathrm{X}-33$ flight trajectories has shown that it is necessary to provide $\pm 15 \%$ roll, pitch and yaw TVC authority with an optional capability of $\pm 30 \%$ pitch at select times during the mission. The TVC performance requirements for the X-33 engine became a major driver in the design of the engine control system.
\end{abstract}

The thrust level of the X-33 engine as well as the amount of TVC are managed by a control system which consists of electronics, instrumentation, propellant valves, electromechanical actuators, spark igniters, and harnesses. The engine control system is responsible for thrust control, mixture ratio control, thrust vector control, engine health monitoring, and communication to the vehicle during all operational modes of the engine (checkout, pre-start, start, main-stage, shutdown and post shutdown).

The methodology for thrust vector control, the health monitoring approach which includes failure detection, isolation, and response, and the basic control system design are the topics of this paper. As an additional point of interest a brief description of the X-33 engine system will be included in this paper.

\section{TABLE OF CONTENTS}
1. INTRODUCTION
2. X33 ENGINE DESCRIPTION
3. ENGINE CONTROL SYSTEM DESIGN
4. ENGINE CONTROL
5. HEALTH MONITORING
6. CONCLUSION

\section{INTRODUCTION}

The $\mathrm{X}-33$ is an advanced technology vehicle to demonstrate the configuration and technologies of a single stage to orbit (SSTO) reusable launch vehicle (RLV) concept incorporating a lifting body design using a linear aerospike engine for propulsion. The $\mathrm{X}-33$ is a single stage, reusable vehicle designed for vertical takeoff, sub-orbital flight and horizontal landing. The RLV program goal is to create a reusable launch vehicle with reduced operational costs and quick turnaround times. The $\mathrm{X}-33$ is a $53 \%$ geometrically scaled replica of the RLV aero-ballistic body configuration. The vehicle configuration is a delta-shaped lifting body with aerodynamic control surfaces. The X-33 will provide functional traceability and scaleability to the RLV. Subsystems of the X-33 are designed to replicate the functions of the RLV and demonstrate key performance enhancing technologies. The $\mathrm{X}-33$ vehicle is depicted in Figure 1.

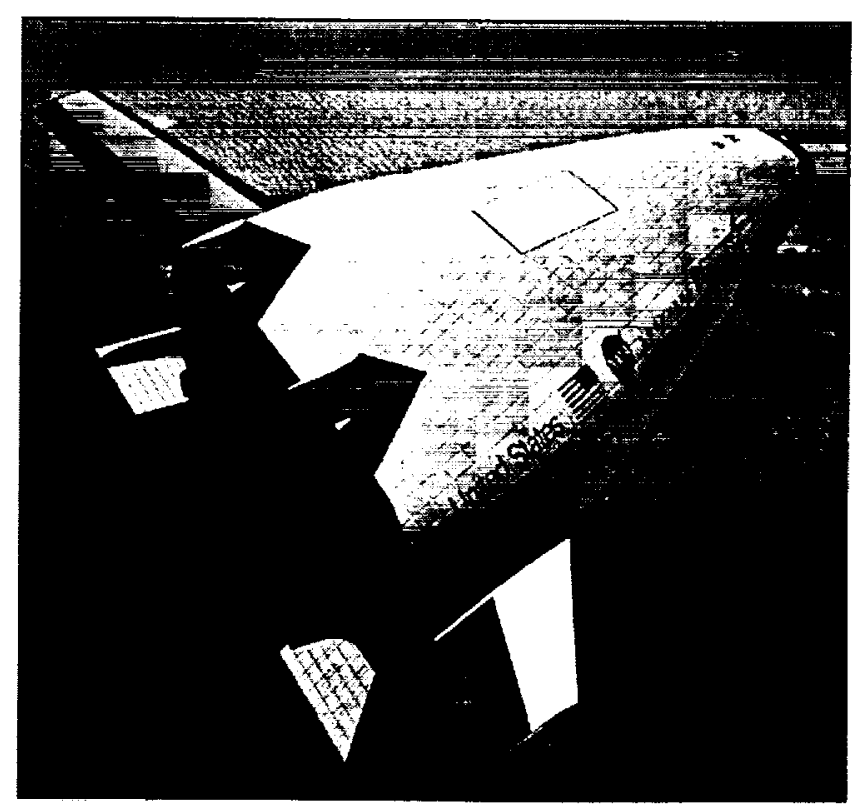

Figure 1. X-33 Vehicle 
The main propulsion for vertical launch and ascent is provided by two XRS-2200 linear aerospike engines using liquid oxygen and liquid hydrogen propellants. The XRS2200 engine is a pump fed, gas generator cycle engine with a truncated ideal linear aerospike nozzle, shown in Figure 2. Each engine can deliver $200,000+$ lbs of thrust at sea level.

The primary advantages of the linear aerospike engine over a conventional bell nozzle engine include altitude compensation, which provides enhanced performance, and lower vehicle weight resulting from the integration of the engine into the vehicle structure. This engine / vehicle integrated structure approach will save weight and concurrently provide more uniform distribution of engine loads into the vehicle structure. A feature of thts integration is the ability to provide thrust vector control (TVC) by differential throttling of the engine, rather than the more conventional approach of gimballing the engine.

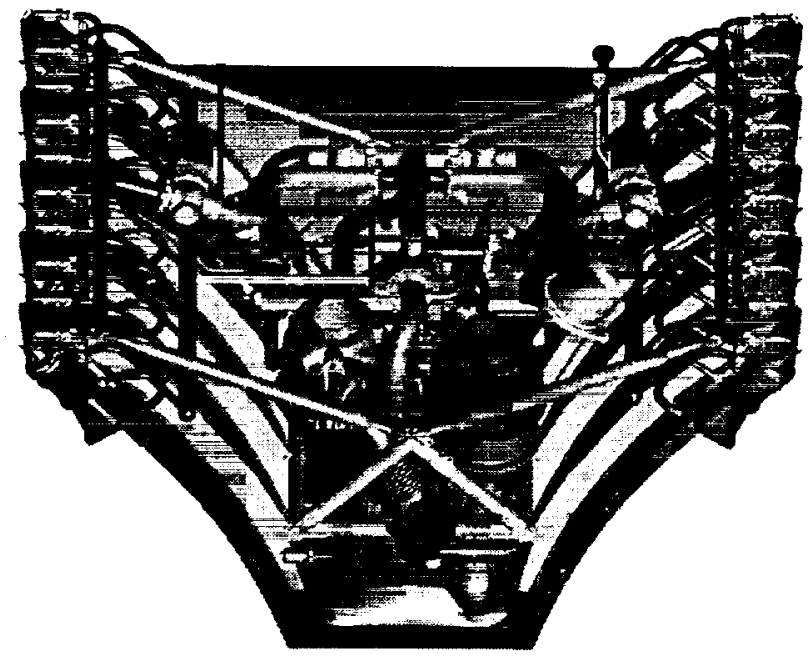

Figure 2. XRS-2200 Engine

A key feature of the X-33 engine is differential throttling for thrust vector control (TVC) used to provide the main source of vehicle attitude control during the powered portion of the flight. An analysis of the X-33 flight trajectories has shown that it is necessary to provide $\pm 15 \%$ TVC control with an optional capability of $\pm 30 \%$ pitch at select times during the mission. The engine requires 1.3 seconds to reconfigure the control elements to support the $30 \%$ pitch capability. This reconfiguration comes with a performance loss which results in the need for making the pitch level optional. The TVC requirements for the X-33 engine became a major driver in the design of the engine control system.

To accomplish the TVC as well as control and monitor the engine's performance an electronic control system was implemented. The architecture chosen was driven by the engine control performance requirements as well as the reliability requirements. To meet the fail-operational requirements of the $\mathrm{X}-33$ vehicle, the engine control system provides redundancy for all critical electrical components. The performance requirements had a significant impact on the response capabilities of the system. These requirements also played a major role in the design of the propellant valves, the electronics, and the methodology of redundancy management. The engine control system operates in conjunction with the vehicle guidance and control system to accomplish overall vehicle control. The engine control system is responsible to provide the following functions:

Engine to Vehicle communication
Closed loop control of engine thrust and
$\quad$ propellant mixture ratio
Closed loop thrust vector control
Real-time engine Health Monitoring
28VDC power distribution
270VDC power control to engine valve actuators
Control of engine purges
Control of engine event sequencing
Perform all checkouts and self-tests
Engine redundancy management

\section{X33 ENGINE DESCRIPTION}

The X-33 main engine is the XRS-2200 linear aerospike rocket engine which provides propulsive thrust by burning a combination of liquid hydrogen and liquid oxygen. The engine employs a gas generator cycle with a single gas generator providing fuel-rich drive gas for the fuel and oxidizer turbopump turbines in a series power drive arrangement. Main combustion gases are generated in a linear row of individual thrusters arranged in two banks. The high pressure combustion gases are expanded against the aerospike nozzle ramp surface to provide propulsive thrust for the flight vehicle. The engine design incorporates existing components from the Apollo/Saturn J-2 and J-2S engines. Two XRS-2200 engines power the X-33 and are arranged side-to-side along the base of the vehicle for efficient packaging and integration with the vehicle airframe.

The most unique feature of the XRS-2200 engine is the linear aerospike nozzle which is a truncated radial in-flow or spike type nozzle. The $\mathrm{X}-33$ engine is mounted to the vehicle such that the nozzle ramps are roughly centered about the pitch axis of the vehicle. Two banks of ten thrust cells each are arrayed on each side of the nozzle along the vehicle-to-engine interface. The primary flow (high pressure gases) is exhausted from the thrust cells and expanded against the nozzle ramp surfaces to provide the altitude compensated portion of the engine thrust. The 
outer surface of the gas flow along each side of the nozzle ramp is a free-jet boundary which expands as the ambient pressure decreases thereby providing altitude compensated thrust performance for sea-level to vacuum operation. Beyond the ends of the nozzle ramp surfaces, the inner surface of the primary flow expands to enclose a recirculating flow field which acts on the nozzle base to contribute additional thrust to the nozzle. A secondary flow (turbine drive gases) is exhausted through the nozzle base and adds to the recirculating flow to increase the base pressure and the overall nozzle efficiency.

The two XRS-2200 engines installed on the X-33 vehicle are designed to be cross-coupled through fuel and oxidizer inter-engine isolation valves to provide a powerpack-out capability. This arrangement allows the powerpack of onte engine to feed the thrusters of both engines in the event that one powerpack becomes inoperable. This feature provides the capability to maintain symmetrical thrust about the vehicle centerline.

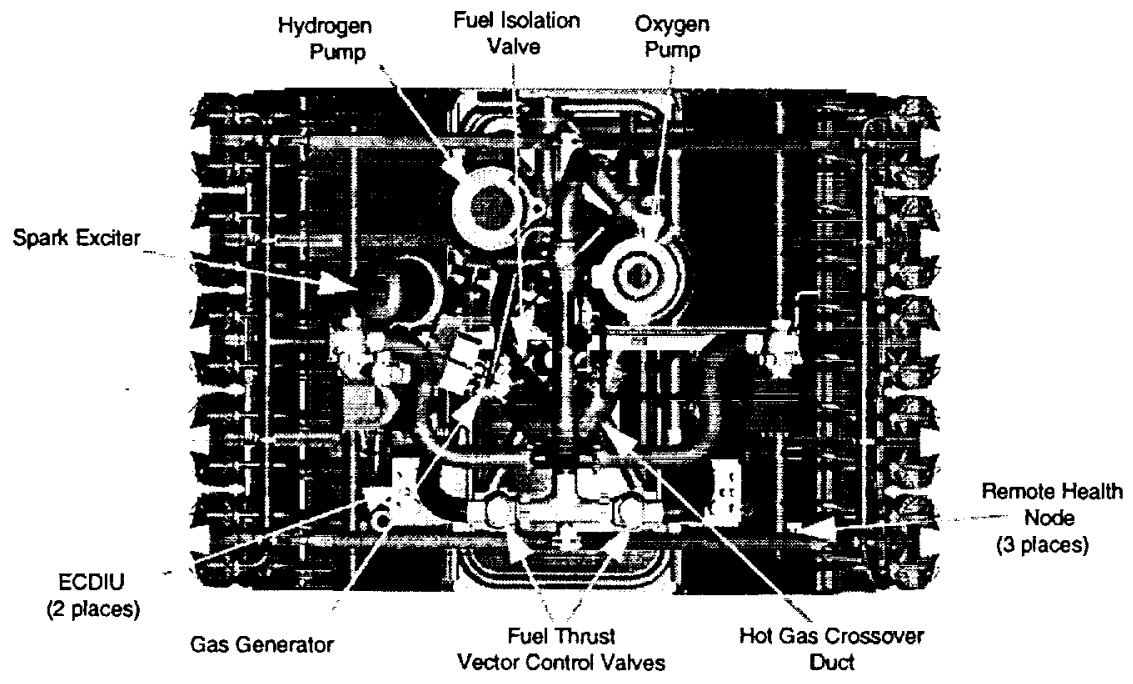

Figure 3. X-33 Engine (Top view)

\section{Thrust Chamber Assembly (TCA)}

The thrust chamber assembly for each engine refers to the combination of the two sets of ten thrust cells and one nozzle ramp each which combined provide the major portion of the engine thrust (a small additional amount of thrust is produced by the GG exhaust through the engine base closeout). Each thrust cell contains an injector which injects the fuel and oxidizer propellants into the thrust cells where combustion occurs to produce hot gas under high pressure which is expelled out the thrust cell, producing 70 to 80 percent of the total engine delivered thrust. The resulting hot gases are expanded against the nozzle ramp surfaces to produce the remainder of the thrust. The thrust is transmitted to the vehicle through the combustors and expansion ramps to the thrust mounts which attach to the vehicle thrust structure.

\section{ENGINE CONTROL SYSTEM DESIGN}

\section{Control System Partitioning}

The control system provides for engine control, checkout, and health monitoring of the XRS-2200 engine system. The XRS-2200 engine control and monitoring system components operate together to meet the control system requirements. It functions in conjunction with the vehicle management computers (VMC's) located on the vehicle, as shown in figure 4 , and consists

\section{Powerpack Assembly (PPA)}

The XRS-2200 engine uses a gas generator (GG) power cycle to drive fuel and oxidizer turbopumps, which furnish the thrust cells and GG with pressurized propellants. The GG creates a fuel rich, hot gas which drives a two-stage turbine on the fuel turbopump followed by a similar twostage turbine on the oxidizer turbopump. After passing through the oxidizer turbine, the hot gas passes across a helium system heat exchanger (HEX) and then is exhausted through the engine base closeout. The combination of the GG, two turbopumps, HEX, and interconnecting hot gas ducting is referred to as the powerpack of the following:

- Two engine control data interface units (ECDIU's)

- Three remote health nodes (RHN's) and associated sensor

- Eleven main propellant valves

- Six fully throttleable electrically actuated valves

- Five pneumatically actuated valves

- Gas Generator (GG) and combustion wave ignition systems

- Pneumatic spin start for engine turbopumps

- Engine pneumatic system

- Instrumentation (pressure, temperature, speed and position sensors) 


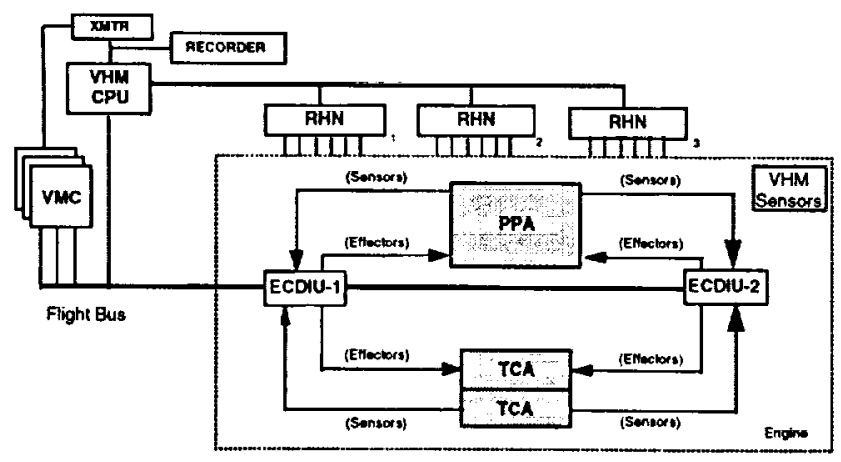

Figure 4. Engine/Vehicle electronics layout

A top-level schematic diagram of the engine control system is shown in Figure 5. Engine control is accomplished by the ECDIU's which receive and execute engine commands from the VMC's, while transmitting engine performance data to the vehicle for recording/transmission by the vehicle health monitoring (VHM) system. The vehicle commands establish the set points for engine power level and TVC control. The ECDIU controls all of the critical operations on the engine. It provides commands to all effectors (valve actuators, solenoids, igniters etc.). All instrumentation necessary for engine control/health monitoring interfaces with the ECDIU, which provides all necessary excitation and signal conditioning. Engine control, checkout and selftest procedures are controlled by the software resident within the ECDIU.
The ECDIU monitors the engines for real-time health status, while the RHN's monitor the engines for long term health. The RHNs are custom devices that have the capability to interface to 24 low-frequency instruments (resistive temperature devices [RTDs], thermocouples, or strain-gauge based pressure sensors) and 8 high-frequency instruments (strain-gauges, accelerometers, etc.). There are three RHNs on each engine to provide for data interfacing of flight test instrumentation (FTI) and engine performance instruments. The data from the RHNs is transmitted to the vehicle health monitoring (VHM) computer for recording.

The control system incorporates two sets of instrumentation: ECDIU instrumentation for real-time performance evaluation and closed loop control, and RHN instrumentation for post-flight engine performance and health evaluation. The ECDIU instrumentation is made up of RTD's, thermocouples, low-frequency pressure sensors, and inductive reluctance speed sensors. The RHN sensors include the above sensor types as well as accelerometers, strain gages and high-frequency pressure sensors.

The primary engine control valves are shown in the schematic in Figure 5 and consist of pneumatically actuated fuel and oxidizer powerpack isolation, inter-engine isolation and combustion wave ignition pilot valves (PPFIV, PPOIV, IEFIV, IEOIV, CWFV and CWOV) and electro-mechanically actuated (EMA) gas generator (GG) and thrust vector control (TVC) valves (GGFV, GGOV, OTVCV and FTVCV). Pneumatically actuated valves are controlled either on or off, and electrically actuated valves

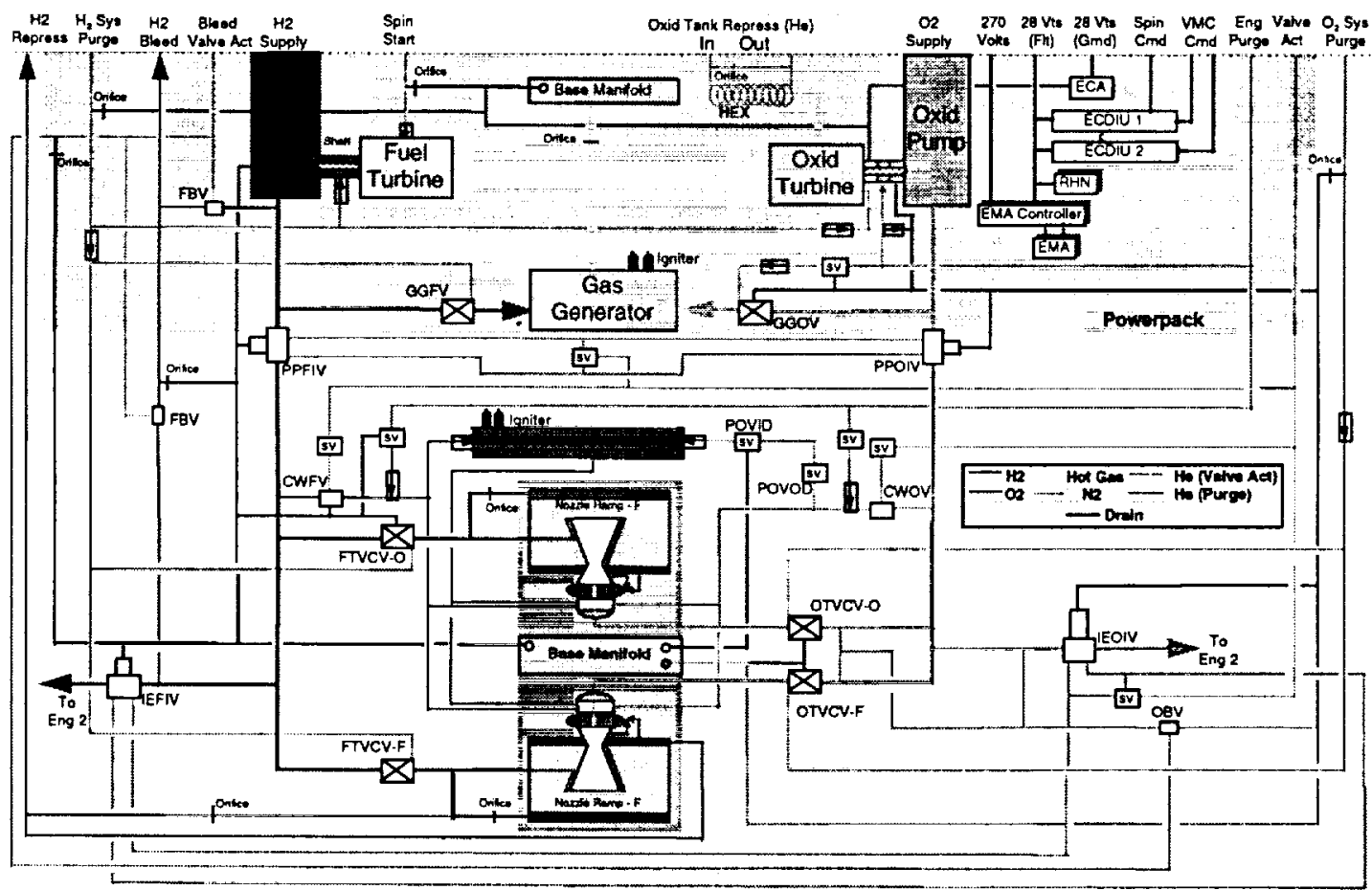

Legend

PPFIV - Powerpack fuel isolation valve

PPOIV - Powerpack oxid. isolation valves

IEFIV - Inter-engine fuel isolation valve

IEOIV - Inter-engine oxid. isolation valve

CWFV - Combustion wave fuel valve

CWOV - Combustion wave oxidizer valve

Figure 5. Top-level Control System diagram 
are modulated to controlled positions by open or closed loop control depending on the engine command being executed. Each EMA is controlled by a separate electronic component. The electro-mechanical actuator electronic controller (EMAEC) maintains the local loop for the EMAs. The ECDIU provides position commands to the EMAECs, which then control the EMAs to that position. The EMAEC was separated from the low-voltage ECDIU due to corona concerns. The EMA's operate with 270 VDC which is provided by the vehicle via the EMAECs.

\section{Component requirements}

The basic requirements for the XRS-2200 engine control system components are described in the following sections.

Engine Control Data Interface Units - The pair of ECDIU's operates in conjunction with the VMC's and the engine sensors, valves, actuators, and spark igniters to provide a system for the control, checkout, and health monitoring of the engine system. The ECDIU's provide the following engine system functions:

- receive electrical power from the vehicle

- provide power switching, conversion, regulation, and distribution for engine electrical components (except for the electro-mechanical actuators)

- receive engine commands from the VMC's

- transmit ECDIU engine data to the vehicle

- exchange data with the other ECDIU

- provide excitation signals, signal conditioning, and multiplexing for sensor interfaces

- provide closed loop control of valve actuator positions

- provide on/off commands to solenoid valves and spark igniters

- provide control system built-in test (BIT) capability

- provide real time health monitoring (sensor validation, redlines, yellowlines)

- perform redundancy management for control components.

Remote Health Nodes - The three RHN's are a standard design used throughout the vehicle which handle 44 channels of data as described in the following:

- 8 high bandwidth (up to $5 \mathrm{KHz}$ )

- 24 low bandwidth (up to $200 \mathrm{~Hz}$ )

- 3 auxiliary (frequency counter, resolver, analog input)

- 8 discrete inputs

The RHN's interface with the VHM sensors and provide the data to the VHM system over a fiber-optic bus for engine system health monitoring data and post-flight assessment of the engine condition and performance. This data is recorded on the vehicle while a select subset of the data is telemetered for real-time ground-based analysis (see figure 4).

Electro-mechanical Actuator Electronic Controllers - The EMAECs provide position control of the six electrically actuated valves by receiving input commands from the ECDIU's, transmitting position commands to the valve actuators, and receiving feedback position data from the valves. The EMAEC's also provide power to actuator heaters and control the actuator brakes. The brakes are designed to mechanically provide friction to the shaft while also removing power from the pulse width modulators (PWMs). Additionally, prior to removing the power from the PWM, the EMAECs freeze the PWM output to increase the braking power. This results in both mechanically and electrically locking the valve position.

\section{$R L V$ traceability}

One key requirement for the $\mathrm{X}-33$ vehicle is to provide traceability to the RLV phase of the program. This requirement is being met in several ways for the control system design. The ECDIUs which use primarily commercial-off-the-shelf (COTS) equipment proves the viability of COTS equipment in space systems, while the RHNs use a fiber-optic bus for communication. The EMAs with EMAECs have great potential in that they enable elimination of hydraulics from the vehicle. Additionally, the software resident in the ECDIUs will use autocoded software with a commercial real-time operating system. Some of these technologies are being used on a closed-loop rocket engine for the first time and will provide significant cost/weight benefits to the RLV program.

\section{Redundancy Management}

The X-33 has a requirement that "In the event of any single electrical component failure, all engine systems shall remain operational." This requirement drove the design into a dual redundant system for all critical electrical components. Extensive analysis of all systems including the ECDIU software has been performed to verify that this requirement was met. The process of system reconfiguration will be verified in a hardware-in-the-loop (HWIL) test facility at NASA-Marshall Space Flight Center (MSFC),

\section{Environmental Concerns}

One of the most challenging aspects of the control system design is meeting the environmental requirements for each 
of the electronic components. The environment of a rocket engine during launch can be very difficult for modern electronics to survive. The thermal requirements of the ECDIU required special mounting provisions along with limitations being placed on the ECDIU software to level the power dissipation.

The vibration levels seen on the XRS-2200 may exceed 1.5 $\mathrm{g}^{2} / \mathrm{Hz}$ in the $100-300 \mathrm{~Hz}$ range. This drove the electronics design in two different directions. The ECDIUs and RHNs added vibration isolators while the EMAECs use primarily surface mount technology with board/component adhesive to survive the vibration.

The explosion proof requirement for any electrical component within an environment that sees hydrogen gas required environmental sealing, similar to that required for humidity prōtection. The basic goal is to prevent 'breathing' during atmospheric pressure changes, thereby preventing the ingestion of hydrogen gas into the electronic component.

\section{ENGINE CONTROL}

Control of the engine during mainstage is performed by the ECDIU's which receive commands from the vehicle and issue commands to the electrically actuated GG and TVC valves. Mainstage engine control consists of thrust control,
MR control, thrust vector control, and GG temperature control. A top level control logic schematic is shown in figure 6. This schematic shows the flow of commands from the vehicle through the ECDIUs to the engine propellant valves.

\section{Gas Generator Temperature Control}

GG temperature control is accomplished via open loop control of the GGFV to specified positions based on the average thrust cell pressure and engine MR commands.

\section{Thrust Control}

Thrust control is accomplished via closed loop control of the GGOV. The ECDIU's convert Pc (chamber pressure) and MR (mixture ratio) commands to desired GG Pc. Actual GG $\mathrm{Pc}$ is measured and provided as feedback information to the ECDIU's which issue commands to the GGOV to achieve the desired GG Pc and engine thrust. The GGOV sets the power available to the thruster banks. The engine can be throttled within a range from $57 \%$ to $100 \%$ power level (P.L.) with a steady state error (Ess) $\leq$ $1 \%$ P.L. and a maximum throttling rate is $30 \%$ P.L./sec. During throttling, the engine MR must stay within the boundaries defined in the operational envelope shown in figure 7. The engine mode determines the P.L. and MR region of operation available for commands.

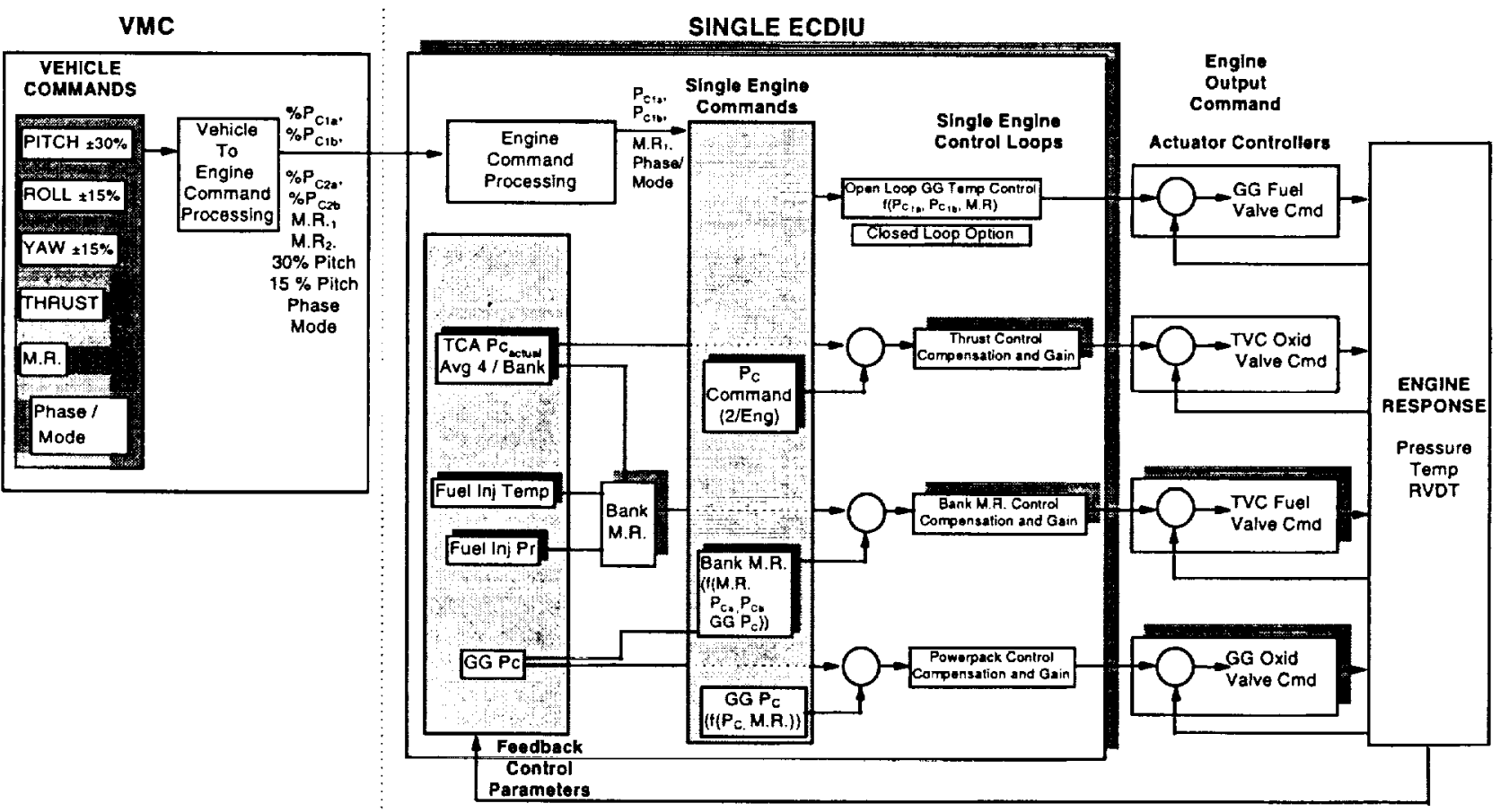

Figure 6. X-33 Control law diagrams 


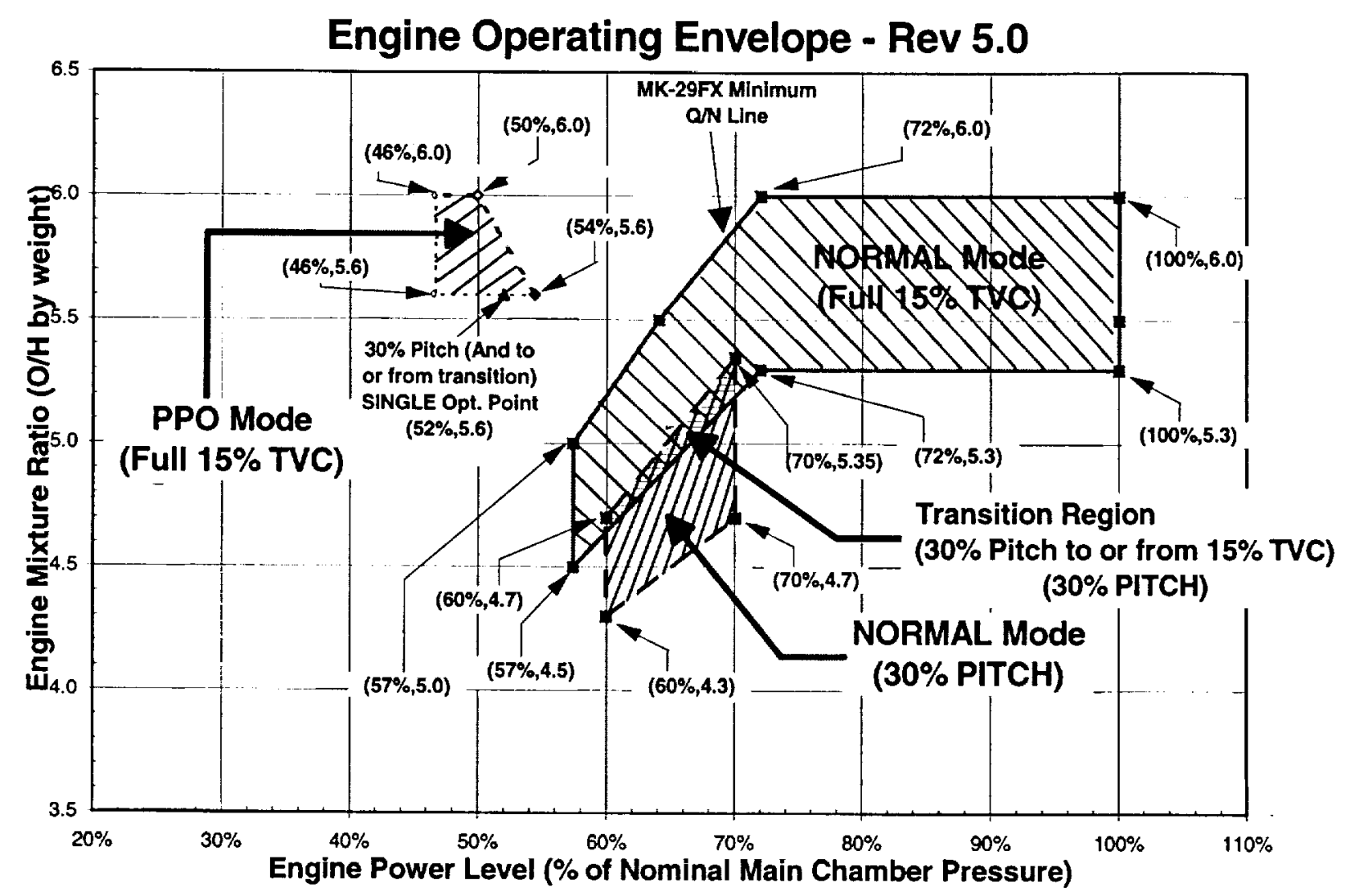

Figure 7. Engine Operating Envelope

For large amplitude excursions (Delta P.L $>0.75 \%$ ), the maximum tracking error between commanded power level and actual power level during a transient will be as shown in figure 8.

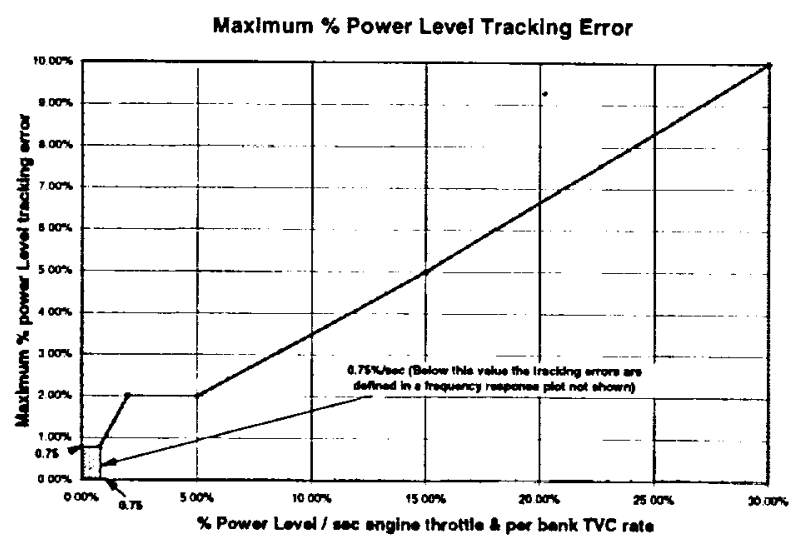

Figure 8. Maximum \% P.L tracking error

Below $0.75 \%$ P.L. the tracking error is defined in gain and phase frequency response plots not shown.

\section{Mixture Ratio (MR) Control}

MR control is accomplished via closed loop control of the two FTVCV's. Fuel injector pressures and temperatures and thruster bank chamber pressure level are provided as feedback information to the ECDIU's which calculate required thruster bank fuel flow and issues commands to the two FTVCV's to achieve the desired MR in each thruster bank. LOX flow is determined based on the measured chamber pressure and calculated fuel flow, and GG flows are calculated based on the GG pressure. The engine can be operated at any MR within the bounds of engine mode region of operation shown in figure 7 , with an actual Ess $\leq 4 \%$ of nominal MR.

\section{TVC Control}

The X-33 vehicle flight control is accomplished by a combination of aero surface deflection and engine thrust vectoring. Engine TVC commands from the vehicle are implemented by closed loop control of the two OTVCV's. Thruster bank chamber pressure levels are measured and provided as feedback information to the ECDIU's which 
issue commands to the two OTVCV's to achieve the desired thrust chamber pressure levels in each thruster bank. The TVC differential throttling capability controls the propellant flowrates to the upper and lower thruster banks on each engine to provide pitch, roll, and yaw control as shown in Figure 9. The maximum rate that TVC commands can be executed is $60 \%$ P.L./sec. The engine system is capable of performing roll and pitch TVC while maintaining the total engine thrust constant. Pitch and roll TVC are performed by adjusting the differential throttling valves on both of the installed engines, and yaw TVC is performed by differentiating the GG power levels to each engine. There are two normal operational modes for TVC; nominal $15 \%$ pitch and $30 \%$ pitch. When operating in the nominal $15 \%$ mode, the engine can be commanded up to $15 \%$ roll, pitch or yaw. When the engine is operating in the $30 \%$ pitch mode, the engine can be commanded up to $30 \%$ pitch, $15 \%$ roll and $7.7 \%$ yaw. Due to the higher operating pressures required in the GG for $30 \%$ operation, there is a minor engine response penalty, and a reduction in GG yaw capability. The pitch option is controlled by a discrete input from the VMC to the ECDIU which switches between the two control laws. During powerpack out (PPO) when only one powerpack is operating, yaw TVC is performed by the differential throttling valves. The cross valves are open allowing propellant to flow to or from engine to engine.

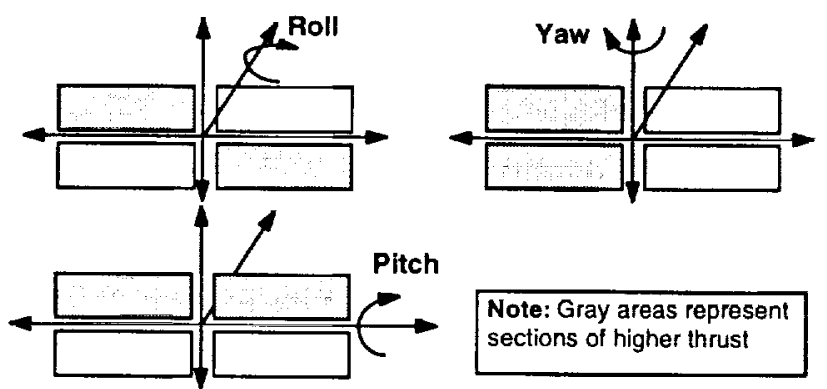

\section{Operational Constraints}

There are certain engine operational restrictions that must be followed for engine hardware protection. In the normal TVC mode of operation, the value of any bank's P.L. must be within $15 \%$ of the average bank's P.L. In addition, each engine must operate within the defined P.L. vs MR operating envelope, see Figure 7. Similar constraints apply for each mode of operation, with additional restrictions during transition between regions of operation.

In addition, at certain combinations of P.L., MR and altitude, the engine experiences a roll control reversal. These combinations must be avoided during flight operation.

\section{HEALTH MONTTORING}

The XRS-2200 health monitoring system (HMS) evaluates the engine system performance and responds accordingly to safely obtain the mission objectives. An integrated systems analysis was conducted to define the requirements for the health monitoring system for detecting unsafe performance, isolating the problem, and responding appropriately. The systems analysis combined the engine instrumentation, event sequencing, control law implementation, turnaround operations, and development testing into an integrated health monitoring system. The health monitoring system architecture encompasses automated pre-launch sequencing checkouts, pre-engine start health monitoring, holddown algorithm, flight safety monitoring, automated post test diagnostics, and ground test safety. The health monitoring approach description follows.

Figure 9. TVC diagrams.

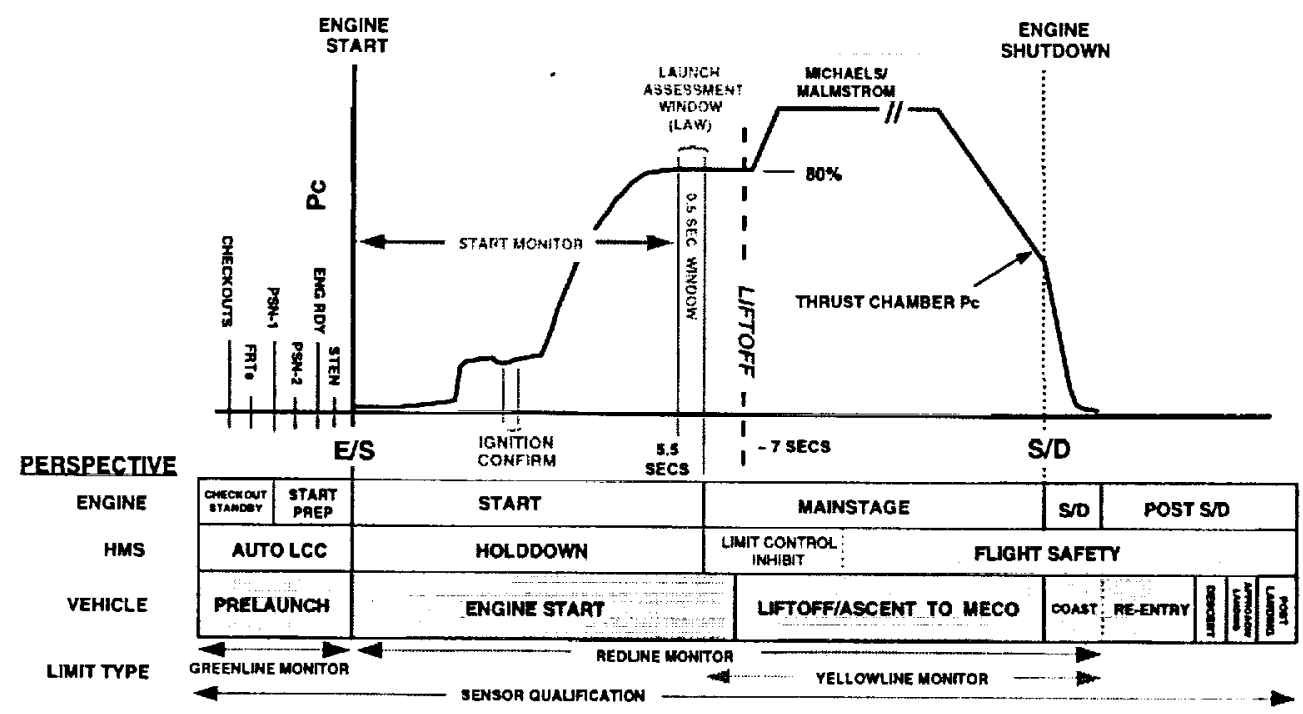

All aspects of the health monitoring system design involved an integrated analysis to establish the HMS requirements through a failure modes cause and effects analysis, structural analysis, functional analysis, instrumentation

selection, and engine system

Figure 10. HMS timeline vs. Main chamber pressure 
performance analysis. In addition, an integrated event sequencing timeline analysis established the operations and time period when monitoring is required. This approach produced a system that safely meets the operational, safety and performance objectives of the program. Figure 10 depicts the modes of HMS and when they are active.

\section{Automated pre-launch sequencing checkouts}

Automated pre-launch sequencing checkouts verify the engine control systems are functional prior to initiating launch sequence operations. Actuator calibration routine (ACAL), actuator checkout module (ACM), pneumatic checkout, electrical system checkouts, ECDIU checkouts, and flight readiness tests (FRT) provide the necessary system verification. ACAL automatically calibrates the actuator position feedback sensors. The signal at the open and closed stops are processed to give the correct position feedback for accurate control. The ACM verifies both channels of the valve actuator are functioning properly. Actuator performance characteristics such as rate, position, command, brake, and switchover performance are verified. The pneumatic system checkout verifies the purge solenoids, pneumatic valve actuation solenoids, and engine system solenoids are functional. The algorithm uses purge pressure, position and current feedback to accomplish the checkout. Electrical checkouts are performed to verify all electrical systems are properly connected and the proper signal path integrity is not compromised. The electrical systems include the ignition system, instrumentation, and the ECDIUs. The final checkout is the FRT. This test simulates the actual countdown and mission from beginning to end. The engine commands, control laws, and software are exercised. Feedback parameters are simulated based on engine valve positions. This test is the overall engine control system check. At this point the engine control system is ready to transition to the launch purge sequence operations (PSN) to prepare for engine start.

\section{Pre-start health monitoring}

Prestart health monitoring verifies proper engine propellant conditioning and launch configuration setup. The monitoring during this period includes leak detection, engine conditioning, engine ready, sensor qualification, and actuator monitoring. Greenline monitoring is the monitoring performed during the pre-start phase to verify the engine is operational. An example of this is leak detection, which verifies the engine internal leakage is not above the safe limit by measuring the temperature of the ducts downstream of the valves. The selected instrumentation detects valve and pump seal leakages. Engine conditioning verifies the engine is in the proper configuration during the prestart period. This includes valve positions, bleed system functions, and purge activity.
Improper engine conditioning is unacceptable for engine performance and will delay countdown until proper conditioning can be verified. In addition, sensor qualification monitoring is active during this period to verify decisions are based on valid data and to verify any data from parameters that will be used in subsequent periods is valid before proceeding with the launch countdown. Actuator monitoring is also accomplished to verify proper valve position and feedback. This is critical to engine control. Engine ready monitoring verifies the conditions are acceptable for engine start. The monitoring includes pump inlet conditions and pneumatic system conditions. When the engine has successfully transitioned into engine ready a signal is sent to the VMC that the start enable (STEN)/ start (STRT) command sequence may be issued.

\section{Holddown Algorithm}

The holddown algorithm, Launch Assessment Window (LAW), evaluates the engine system operation during start up and prior to liftoff. The monitoring consists of ignition detection, thrust build up, actuator monitoring, sensor qualification, and launch assessment window. Ignition detection confirms the main combustion system and the gas generation systems have properly ignited and combustion is active. Without proper ignition, the system can not safely continue operation. The thrust build up check monitors engine performance and system sequences as the system bootstraps up to mainstage. This monitoring will be based on test experience from the development program. A database will be established and implemented into the health monitoring system. Sensor qualification and actuator monitoring are active during this time period. The LAW is a check of the engine system, including the engine hardware, software, and control laws, at 80 percent powerlevel from 5.5 to 6.0 seconds. Successful completion of the LAW provides the vehicle with the engine authorization to command liftoff. In the event of a LAW failure, the engine will autonomously command engine shutdown. The threshold monitors during this period will be based on a statistical approach using multiple engine parameters.

\section{Flight Safety Algorithm}

The flight safety algorithm monitors the engine system from LAW completion to landing or ECDIU power termination. Control parameter monitoring, powerpack out monitoring, and yellowline monitoring encompass the flight safety. The control parameters (valve position, pressure, temperature) are monitored to determine valid feedback signal which is required to control the engine thrust and mixture ratio. For loss of control parameter, a yellowline condition will be 
invoked to continue the mission at a reduced performance or redundancy. Actuator performance is also evaluated to maintain proper valve position. The engine control system has the capability of switching over to the redundant actuator channel if loss of control occurs on the first channel. If the engine system reaches a point where unsafe operation of one of the powerpacks occurs (redline), a powerpack out command may be initiated shutting down a single powerpack and operating both engines with one powerpack at a reduced engine thrust. Yellowline monitors will also be utilized to prevent/delay implementation of the powerpack out operating mode. Options include powering down both engines or limiting the valve positions, which could reduce power and/or TVC capability. Development of this logic is integrated with the flight trajectory due to the impacts on vehicle control. The yellowlines will be developed and validated during the ground test program.

\section{Turnaround Maintenance}

Turnaround maintenance and next flight clearance utilize data analysis techniques to determine the state of engine hardware and assist in the turnaround process by eliminating inspections and isolating damaged hardware. The goal of post flight data analysis is to reduce operations and maintenance costs where turnaround time is a major cost driver. The integrated health monitoring focuses on the process of monitoring the engine for the purpose of assessing engine health. This is performed through intrusive and non-intrusive sensors that feed into and are compared to a historical database for performance / life trends assessment. To accomplish this task, a post flight database and expert system will be developed/refined during the ground test program. The system will be capable of storing and manipulating performance and HMS data from all tests, engine component design data, and component manufacturing data. The system will automatically analyze data to assist in determining the condition of the engines for next test./ flight. Next flight readiness prediction will be assessed through statistical analysis, historical data and ground test data. The system is called the Post Test Diagnostic System (PTDS). The database and expert system will be developed utilizing the engine model and actual hotfire test results. Sensor selection and placement included addressing issues such as health monitoring and involved experts from each technical discipline to determine the best sensor suite for providing data which would allow for the optimal assessment of engine health.

\section{Ground Test Safety}

The ground test safety system provides for a conservative test program that protects the hardware. Due to the high cost of engine hardware, the ground test program's HMS objective is to protect the engine. As compared to the vehicle's HMS objective, which is to extend mission duration even at the cost of the engine. This system utilizes multiple systems to assure ground test safety objectives which include: ECDIU monitoring, facility monitored engine parameters, facility monitors, observer monitors, and system of safety (SOS) development. The ECDIU monitoring for ground test safety will not be the same as performed for flight monitoring. The ground test program will determine what monitors are the most effective and have the best potential benefit for the flight program. Facility monitors include the Radial Accelerometer Safety Cutoff System (RASCOS), Real Time Vibration Monitoring System (RTVMS), and the High Speed Observer. These systems give the engine additional protection and monitor one of the best indicators of engine / pump health; the vibration signature. Facility and observer monitors protect both the facility and the engines and encompass many failure scenarios. History indicates these systems catch what other systems do not detect. An example of this is seen in plume spectrometry analysis, which analyzes the content of the engine exhaust. Significant amounts of certain elements may indicate a potential catastrophic failure is imminent. Finally, a system of safety (SOS) algorithm will be developed in monitor mode only for future use. The system compares the actual engine performance to a real time model output. The logic developed utilizes the interrelationship of the engine parameters to determine engine health. Conceptually, it is a system approach to health monitoring because it does not rely on one parameter to make a decision. The development program will prove the feasibility of the SOS monitor for use on the RLV program.

\section{CONCLUSION}

The unique integration of the linear aerospike engine into the vehicle structure allows for a reduction of the length of the launch vehicle, thereby creating significant weight savings. The differential throttling concept permits steering of the vehicle without the imposition of heavy and expensive hydraulic actuator systems, as well as the additional complexity of designing the engines for gimballing. This "built in" capability does complicate the engine control system, but does not significantly impact hardware complexity, as most of the TVC components exist to perform the basic engine operating functions.

A detailed assessment was performed to attain a control system that met the system requirements while maintaining reasonable cost controls.

The control system design incorporates redundant electronic controllers, redundant instrumentation, 
redundant EMAs with separate EMA controllers, valves and solenoids to provide for engine control and health monitoring. A fail-safe approach was used for all single string components, while redundancy was used when this was not possible. An example of this is that all single string solenoid failures place the associated valve in its nominal position during flight.

To provide for traceability, the technical advancements of the X-33 control system seek to prove the validity of COTS components and fiber-optics for use on the RLV.

The extensive use of health monitoring will significantly reduce the operational costs while increasing the safety of the future reusable launch vehicle.

\section{REFERENCES}

[1] XRS-2200 Engine Baseline Description Document (RD97-260), Oct. 101997

\section{BIOGRAPHY}

Jerry Jackson is a lead engineer on the X33 Controls Team for Rocketdyne, div. of Boeing North American Inc. Jerry received an MS in electrical engineering from California State University, Northridge in 1992. He has been involved in control system design/development on several major programs including the Space Shuttle Main Engine (SSME) and Kinetic Energy Weapons (KEW). His basic field of expertise is redundancy management, electronic system design and software.

Jeff Klop is a lead engineer on the X33 Controls Team for Rocketdyne, div. of Boeing North American Inc. Jeff received a $\mathrm{BS}$ in electrical engineering from Bradley University in 1986. He has been involyed in control system design/development on several major programs including the Space Shuttle Main Engine (SSME) and International Space Station (ISS). His basic field of expertise is control law development and electronic system design.
Erich Espenschied is a lead engineer on the X33 Controls Team for Rocketdyne, div. of Boeing North American Inc. Erich received a BS in mechanical engineering from University of California, Davis in 1989. He has been involved in engine system analysis on several major programs including the Space Shuttle Main Engine (SSME). His basic field of expertise is engine performance analysis and health monitoring development. 